\title{
The Impact of Retail Rate Structures on the Economics of Commercial Photovoltaic
}

\section{Systems in California}

\author{
Andrew Mills*, Ryan Wiser, Galen Barbose, William Golove \\ Ernest Orlando Lawrence Berkeley National Laboratory, 1 Cyclotron Road, MS 90R4000, \\ Berkeley CA 94720, USA
}

\begin{abstract}
:
This article examines the impact of retail electricity rate design on the economic value of grid-connected photovoltaic (PV) systems, focusing on commercial customers in California. Using 15-minute interval building load and PV production data from a sample of 24 actual commercial PV installations, we compare the value of the bill savings across 20 commercial-customer retail electricity rates currently offered in the state. Across all combinations of customers and rates, we find that the annual bill savings from PV, per $\mathrm{kWh}$ generated, ranges from $\$ 0.05 / \mathrm{kWh}$ to $\$ 0.24 / \mathrm{kWh}$. This sizable range in ratereduction value reflects differences in rate structures, revenue requirements, the size of the PV system relative to building load, and customer load shape. The most significant rate design issue for the value of commercial PV is found to be the percentage of total utility bills recovered through demand charges, though a variety of other factors are also found to be of importance. The value of net metering is found to be substantial, but only when commercial PV systems represent a sizable portion of annual customer load. Though the analysis presented here is specific to California, our general results demonstrate the fundamental importance of retail rate design for the customer-economics of grid-connected, customer-sited PV.
\end{abstract}

\footnotetext{
* Corresponding author. Tel.: +1510 486 4059; fax: +1510 486 6996. E-mail addresses: admills@lbl.gov (A.Mills), rhwiser@lbl.gov (R. Wiser), glbarbose@lbl.gov (G. Barbose), and whgolove@chevron.com (W. Golove).
} 
Keywords: Photovoltaics, Retail rate design, Net metering

\section{Introduction}

The solar power market is growing at a quickening pace, fueled by rapid technological advancements, concerns about global climate change and energy security, and an array of national and local initiatives aimed at improving the value proposition of photovoltaic (PV) systems. The United States represents the world's third-largest market for PV installations, behind Germany and Japan, and installations in California represent over $75 \%$ of the entire U.S. market for grid-connected PV. Though solar policies in the U.S. take many forms, they commonly include up-front capital cost rebates or ongoing production incentives, supplemented by net metering requirements to ensure that customer-sited PV systems offset the full retail rate of their customer-hosts (see, e.g., Bolinger and Wiser 2002; Cooper et al. 2006).

Somewhat less recognized is the role of retail rate design, beyond net metering, on the customer-economics of grid-connected, customer-sited PV. Over the life of a PV system, utility bill savings represent a substantial portion of the overall economic value received by the customer. ${ }^{1}$ At the same time, the design of retail electricity rates, particularly for commercial and industrial customers, can vary quite substantially. Retail rates may contain flat or time-varying energy $(\$ / \mathrm{kWh})$ charges and, for commercial customers, often demand $(\$ / \mathrm{kW})$ charges as well. Understanding how specific differences in rate design affect the 
value of customer-sited PV is therefore essential to supporting the continued growth of this market.

This article, which presents select results of a larger study by Wiser et al. (2007), examines the impact of retail rate design on the economic value of customer-sited PV for commercial customers in California. We focus on California for two primary reasons. First, California represents the largest market for PV in the United States and, with a newly established \$3.3 billion incentive program intended to motivate 3,000 MW of PV installations by 2016, is likely to remain a major market for PV globally. Second, the state's electric utilities have developed a wide range of retail rate structures, allowing for a thorough analysis of the impact of variations in rate design on the economics of commercial PV systems. Consequently, though our analysis is specific to California, our general results will be of some use to other states and countries that are seeking to support customer-sited PV.

One can discuss the value of PV systems from a variety of perspectives. From the perspective of the electric utility and its ratepayers, much of the value of PV comes in the form of avoided fixed and variable costs associated with the generation, transmission, and distribution of electricity. ${ }^{2}$ From the perspective of society at large, the value of PV includes the same set of avoided costs enjoyed by the utility, and in addition avoided externalities (e.g., associated with emissions or land use) and other benefits. Finally, from the perspective of a customer with a PV system installed at its facility, the economic value of a PV system derives in large part from savings on electric utility bills. It is this last perspective that is the focus of this article. 
We focus, in particular, on 20 commercial and industrial electricity rates currently offered by the five largest electric utilities in the state: the Los Angeles Department of Water \& Power (LADWP), Pacific Gas \& Electric (PG\&E), Southern California Edison (SCE), San Diego Gas \& Electric (SDG\&E), and the Sacramento Municipal Utility District (SMUD). We compute the annual electricity bill savings that would be realized on each of these rates by 24 actual commercial PV installations in California, using contemporaneous, 15-minute interval building load and PV production data from those sites. We then compare the calculated bill savings across rate schedules and customer sites, and isolate differences related specifically to rate design, as well as differences related to other factors, including: the average cost of electricity on each rate, the customer load shape, the PV production profile, and the size of the PV system relative to customer load.

The results of this analysis should be of value to: regulators and policymakers who have the authority to approve the design of retail electricity tariffs and want to understand the impact of those tariffs on the economics of commercial PV systems; stakeholder groups who wish to influence those rate design decisions; end-use customers who need to estimate the potential bill savings from PV installations; and PV retailers and consultants who have an obligation to assist customers in determining the value of PV investments and in selecting the retail rate that will maximize that value. We encourage further work of this type in other jurisdictions where the temporal profile of PV output differs, and where retail rate structures are dissimilar to those in California. 
The remainder of this article is structured as follows:

- Section 2 highlights the basic characteristics of commercial electricity tariffs in the United States, elucidates the principles of rate design, and reviews previous research upon which our work builds.

- Section 3 describes the retail rates, customer load and PV data, and basic analysis methods used in this article.

- Section 4 presents the customer-value of PV across the rate schedules analyzed, focusing on the base-case assumptions in which net metering is available and the customer remains on the same retail rate before and after the installation of a PV system.

- Section 5 relaxes the earlier assumption that customers must stay on the same rate before and after installing a PV system, and demonstrates the potential value of rate switching, especially when PV represents a sizable portion of facility load.

- Section 6 estimates the value of net metering under different retail rate structures, customer load profiles, and PV penetration levels.

- $\quad$ Section 7 concludes with a summary of our major findings.

\section{Rate Design Methods, Principles, and Applications}

\subsection{Retail Rate Treatment of Customer-Sited PV}

In many European countries, customers are compensated for their PV output through a feed-in tariff, and PV systems are therefore located on the utility's side of the electricity 
meter. In contrast, customers in the U.S. are compensated for their PV output indirectly, by using the PV system to meet onsite electrical load and thereby avoiding the purchase of electricity at retail prices. Many states have adopted policies to support this type of arrangement. First, some states, including California, have eliminated standby and backup charges for customer-sited PV; these charges are typically intended to recover the fixedcosts of serving customers in the event that an onsite generator does not fulfill the customer's entire electricity demand. Second, many states have adopted net metering requirements. Though the specific design of net metering rules and their attractiveness to PV customers varies considerably, generally speaking, net metering allows customers with PV systems to be credited for the generation from those systems at the retail rate prevailing at the time of production, regardless of the customer load at that time (Hughes and Bell 2004; Cooper and Rose 2006). Given the temporal profile of PV production, there may be periods when PV production exceeds customer load; net metering allows these differences to be "netted" over a longer period of time (e.g., one month or one year). Beyond these policies, the reduction in the customer's utility bill, and thus the overall customereconomics of PV, is also strongly affected by the structure of retail electricity tariffs.

\subsection{Rate Design for Commercial Customers in the United States}

Electric utility rates are set with oversight from regulators to recover the cost of providing service and to provide a reasonable return on investment for utility shareholders. In addition to overall utility cost recovery, regulators balance several goals in setting retail electricity rates. One important goal is economic efficiency, meaning that customers should be charged rates that reflect the cost to the utility of providing an additional unit of 
service to that customer. Other important goals include equity, rate stability, innovation, administrative ease, and environmental protection (Bonbright 1961; Weston 2000).

In evaluating the economic efficiency of different rate structures, it is important to understand what drives utility costs in the short- and long-term, acknowledging that the drivers may differ for generation, transmission, and distribution. Cost drivers may include the number of customers, customer and/or system peak load, and the amount of energy consumed. These drivers correspond to three distinct types of charges for commercial customers:

- Fixed recurring customer charges, denominated as a fixed monthly or daily charge;

- Demand charges, assessed on "peak" customer demand (kW), often determined within a single 15-minute interval; and

- Volumetric energy charges, assessed on energy consumption (kWh), and either fixed in value or time-varying.

Two of the primary challenges of rate setting are determining how to divide costs among these three categories and how to specifically design each charge, taking into consideration the various objectives of rate design. Substantial debate exists on these topics (Bonbright 1961). In part as a result, the allocation of the total customer bill among these components, as well as the structure of the individual components, can and do differ significantly across rates. Fixed recurring charges are generally a very small portion of the overall bill, however; as a result, in this article we focus on how the bill savings from customer-sited 
PV is affected by the allocation of utility bill costs between demand and volumetric energy charges, and by the structure of these two types of charges.

\subsection{Impact of Retail Rate Design on the Value of PV: Literature Review}

Predicting the effect of PV systems on volumetric energy charges is relatively straightforward, and requires only a temporal PV production profile. In contrast, calculating reductions in demand charges is more complicated and customer specific, as these savings depend on the precise temporal correlation between PV system output and building load. Accurate calculation of demand charge reductions may therefore require customer-specific 15-minute PV production and contemporaneous load data. Furthermore, demand charge savings may change over time as customer load shape varies, and are therefore less predictable than energy charge savings. As a result, it is not abnormal for potential solar customers to either ignore or heavily discount any claimed or estimated demand savings, and for solar advocates to call for optional "PV-friendly" rates that eliminate or significantly reduce demand charges and that instead recover most costs through volumetric energy charges (Smeloff et al. 2006, WGA 2006).

A number of authors have examined the extent to which PV systems can reduce peak customer demand and/or demand charges. Perez et al. (1997) estimate the customer-based effective load carrying capacity (ELCC) of PV systems for a range of customer load types. ${ }^{3}$ The study finds that PV systems most effectively reduce demand in air-conditioned office buildings. Hoff et al. (1992) use load data from a single office building and simulated PV data to show that, for a PV system sized much smaller than the maximum demand of the 
building, the PV system leads to substantial reductions in both demand and energy charges using two specific electricity tariffs. The authors also find that the monthly demand reduction from the PV system declines from an average of $70 \%$ of PV capacity to less than $10 \%$ of PV capacity as the PV system size is increased relative to peak building load. Hoff et al. explain that this is due to the peak demand shifting from the afternoon, when PV production is highest, to times when the PV system is not expected to produce significant amounts of electricity. Bhattacharjee and Duffy (2006) performed a case study analysis of a PV system installed on a government building in Massachusetts and show how the payback period for the system decreases if demand charge savings are incorporated in the economic analysis.

Other studies have examined a broader range of issues related to rate design and PV, including Hoff and Margolis (2004) and Pop (2005), which compare the value of PV systems for residential customers under time-of-use (TOU) rates versus standard flat rates. Herig and Starrs (2002) discuss the implications of fixed versus volumetric charges, as well as standby and back-up rates, on the economics of solar installations. Johnston et al. (2005) explore the impact of standby charges on distributed generation on a qualitative basis, while Firestone et al. (2006) establish the quantitative impact of standby charges and other rate structures on distributed generation in New York and California. Cooper et al. (2006) provide a recent review of the status and importance of net metering at the state level, while Duke et al. (2005) summarize the public policy rationale for net metering. 
Based on this review of previous work it is apparent that several other authors have explored the value of PV systems under various rate designs. This literature has not systematically estimated avoided utility bill costs to commercial customers across multiple actual metered building load and PV production combinations, however, or under a large number of different rate structures. The work presented here fills that void.

\section{Data and Analytical Approach}

\subsection{Retail Rates Schedules}

The 20 retail electricity rates analyzed in this article are listed in Table 1, and represent the full set of standard tariffs offered by the five largest utilities in California to net-metered commercial and industrial (C\&I) customers with peak demands greater than $100 \mathrm{~kW}{ }^{4}$ Most of these rates include both energy charges and demand charges. The energy charges can be distinguished based on how the energy charge rate (denominated in $\$ / \mathrm{kWh}$ ) varies over time: flat rates remain constant all year long; seasonal rates vary between winter and summer; and time-of-use (TOU) rates vary throughout each day and are typically highest during the summer on-peak hours. The demand charges can be distinguished in two ways: by the period over which peak demand is defined (either annually, monthly, or during specific time-of-day periods) and whether the demand charge rate (denominated in $\$ / \mathrm{kW}$ ) differs by season or is constant year-round. 
Table 1. Commercial Rate Schedules Included in Analysis

\begin{tabular}{|c|c|c|c|c|}
\hline \multicolumn{5}{|c|}{ Rates Evaluated in Analysis } \\
\hline \multirow{2}{*}{ Utility } & \multirow{2}{*}{ Rate Name } & \multirow{2}{*}{$\begin{array}{c}\text { Energy Charge } \\
\text { Type }\end{array}$} & \multicolumn{2}{|c|}{ Demand Charge Type } \\
\hline & & & Facility Charge & Demand Charge \\
\hline \multirow{2}{*}{ LADWP } & $A-2, A$ & Flat & Annual, Fixed & Monthly, Seasonal \\
\hline & $A-2, B / A-3, C$ & TOU & Annual, Fixed & TOD, Seasonal \\
\hline \multirow{6}{*}{ PG\&E } & A-1 & Seasonal & - & - \\
\hline & A-6 & TOU & - & - \\
\hline & $A-10$ & Seasonal & - & Monthly, Seasonal \\
\hline & A-10 TOU & TOU & - & Monthly, Seasonal \\
\hline & E-19 & TOU & Monthly, Fixed & TOD, Seasonal \\
\hline & $\mathrm{E}-20$ & TOU & Monthly, Fixed & TOD, Seasonal \\
\hline \multirow{6}{*}{ SCE } & GS-2, Non-TOU & Seasonal & Monthly, Fixed & Monthly, Seasonal \\
\hline & GS-2, TOU Option A & TOU & Monthly, Fixed & - \\
\hline & GS-2, TOU Option B & TOU & Monthly, Fixed & Monthly, Seasonal \\
\hline & TOU-GS-3 Option A & TOU & Monthly, Fixed & - \\
\hline & TOU-GS-3 Option B & TOU & Monthly, Fixed & TOD, Seasonal \\
\hline & TOU-8 & TOU & Monthly, Fixed & TOD, Seasonal \\
\hline \multirow{2}{*}{ SDG\&E } & AL-TOU & TOU & Monthly, Fixed & TOD, Seasonal \\
\hline & A-6 TOU & TOU & Monthly, Fixed & TOD, Seasonal \\
\hline \multirow{4}{*}{ SMUD } & GS-Demand & Seasonal & Annual, Fixed & - \\
\hline & GS-TOU3 & TOU & Annual, Fixed & TOD, Seasonal \\
\hline & GS-TOU2 & TOU & Annual, Fixed & TOD, Seasonal \\
\hline & GS-TOU1 & TOU & Annual, Fixed & - \\
\hline
\end{tabular}

\subsection{PV Production and Building Load Data}

We obtained 15-minute interval PV production and customer load data for 24 actual commercial sites with PV installations in California. Each dataset includes at least one full year of PV production and building load data. The 24 customer load/PV datasets are diverse in geographic location, PV system size, and customer load shape. In particular, our sample includes many customers whose diurnal load shapes have afternoon peaks (typical of office buildings and retail establishments) as well as a number of facilities with relatively flat diurnal load shapes or inverted load shapes where load is greatest during off- 
peak periods. ${ }^{5}$ The raw PV production and building load data were cleaned to remove seemingly inaccurate spikes in load and solar data, error tags, and other anomalous data points. $^{6}$

\subsection{Analysis}

For each combination of the 20 rate schedules and 24 PV/load datasets, we calculate the value of utility bill savings per $k W h$ generated, according to the following expression:

$$
\text { Value of } P V=\frac{\text { Total Bill without } P V-\text { Total Bill with } P V}{\text { Annual PV Energy Production }} \quad(\$ / \mathrm{kWh})
$$

Expressing the rate-reduction value of PV on a per kWh basis, rather than in absolute dollar terms, serves two purposes. First, it allows us to abstract from the specific size of the PV system, since it is a foregone conclusion that larger systems will generally produce larger absolute bill savings. Second, commercial customers in the United States are increasingly choosing to finance their PV systems through Power Purchase Agreements, whereby the customer purchases the PV output from a third-party owner on a per kWh basis; expressing the value of PV in the same units more readily allows for a direct comparison between the financial costs and benefits of PV from the customer's perspective under this type of arrangement.

The rate-reduction value of PV depends, in part, on how much of the customer's gross electricity demand is met by the PV system. To isolate this effect, for each of the 24 sites, 
we scale the PV production so that annual PV production is equal to specific percentages of the gross annual building consumption. We refer to these percentage values as $P V$ penetration levels and, in presenting our results, we focus primarily on PV penetration levels of $2 \%$ and $75 \%$, as representative boundary cases.

In our initial analysis, we assume that customers remain on the same retail rate before and after the installation of a PV system, and that PV output is net metered according to the specific net metering rules of each utility. However, we also conduct separate analyses in which each of these assumptions is relaxed. In one alternate scenario, we calculate the value of PV under the assumption that customers choose the bill-minimizing rate before and after PV installation, from among each set of rates offered by each utility to a common class of customers (e.g., the set of rates offered by PG\&E to customers with peak demands of 200-500 kW). This analysis helps to reveal which rate design feature(s) dominate in determining the optimal rate for customers with PV and also illustrates the value of offering multiple rate options to customers with PV. In another alternate scenario, we calculate the value of PV under the assumption that net metering is not available, in order to show the financial losses that commercial PV customers in California might bear if net metering were eliminated and replaced with an alternate compensatory structure.

\section{Results: Value of Commercial PV in California with No Rate Switching}

In this section we begin by presenting basic results on the electricity bill-savings value of commercial PV systems in California assuming that each customer remains on the same 
retail rate schedule before and after the installation of the PV system, and that net metering is available. We then explore in more detail variations in this value that depend on differences in rate levels and rate design, as well as variations in customer load profiles. We conclude the section by examining the relative impact of customer specific factors and rate structure variables in determining the bill-reduction value of commercial PV systems.

\subsection{Value of PV By Rate Structure}

Figure 1 summarizes the estimated rate-reduction value of commercial PV in California for each of the 20 retail rates in our sample, at $2 \%$ and $75 \%$ PV penetration levels. The central tick-marks in the figure represent median values across the 24 customers, while the error bands represent the $10^{\text {th }}$ and $90^{\text {th }}$ percentile values.

The figure shows that the value of PV does, indeed, vary widely across rates and customers. For example, on LADWP's A-2, A rate, some customers in our sample would receive bill savings of just $\$ 0.05 / \mathrm{kWh}$, while customers on SCE's TOU GS-3 Option A rate could receive bill savings of $\$ 0.20 / \mathrm{kWh}$ or more. The highest bill savings in the dataset was nearly $\$ 0.24 / \mathrm{kWh}$ for a single customer on SDG\&E’s AL-TOU rate.

Focusing on the median values reveals differences due specifically rate design and overall rate level. At $2 \%$ PV penetration, the median value of PV among the 24 customers varies by nearly a factor of two across the 20 rates in our sample, from $\$ 0.10 / \mathrm{kWh}$ to $\$ 0.18 / \mathrm{kWh}$. 
At 75\% PV penetration, the variation in median values is even greater, ranging from $\$ 0.06 / \mathrm{kWh}$ to $\$ 0.18 / \mathrm{kWh}$.

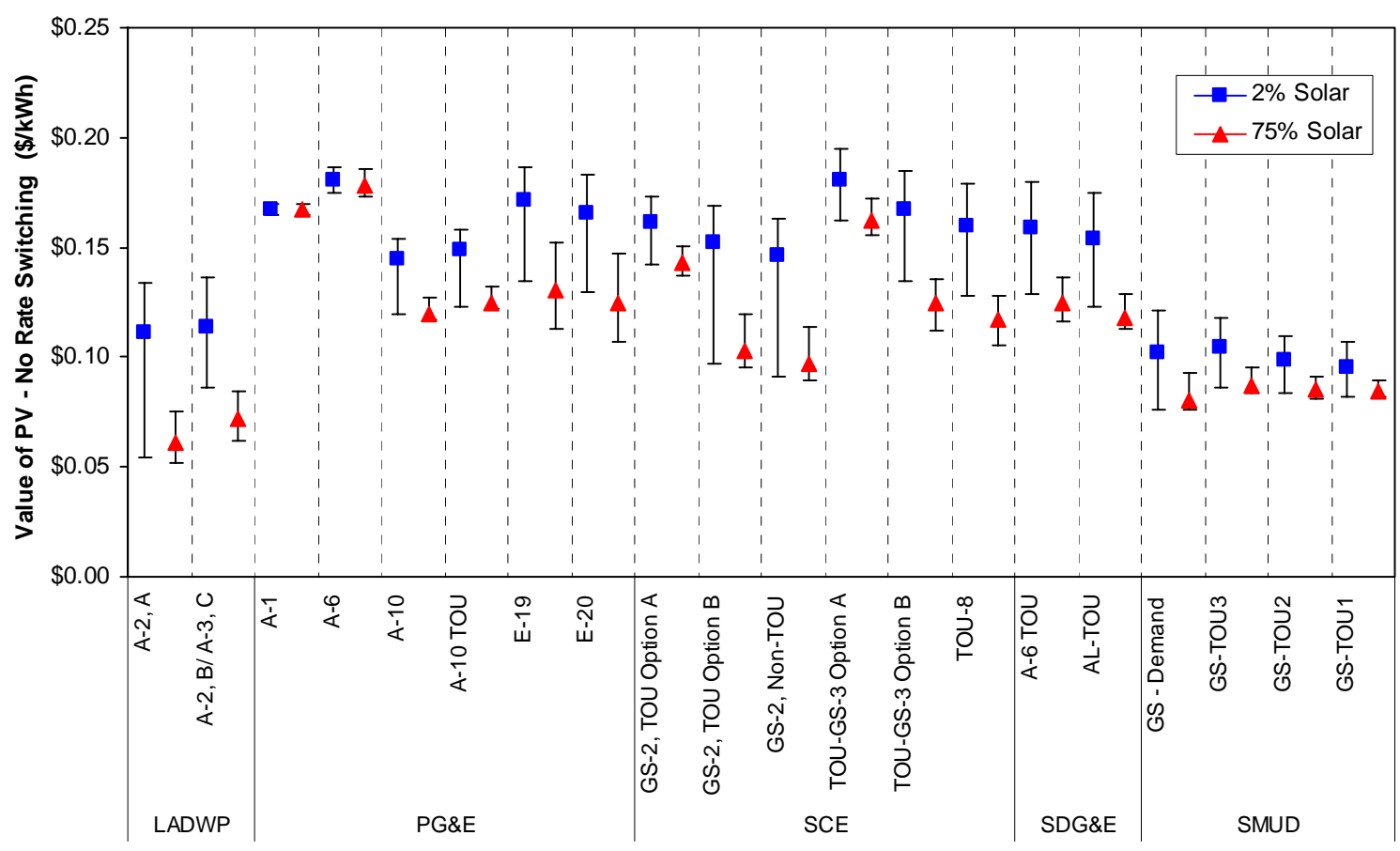

Median value with error bars for $10^{\text {th }}$ to $90^{\text {th }}$ percentile range

Figure 1. Value of PV at Different Levels of Penetration, by Rate Structure

From these results alone, two specific differences among rates can be observed. First, on most rates, the per-kWh rate-reduction value of PV declines when PV penetration increases from $2 \%$ to $75 \%$. This effect, however, is much more pronounced for some rates than for others. For example, for LADWP's A-2, A rate, the median value of PV drops off by one half when PV penetration is increased from $2 \%$ to $75 \%$. At the other end of the spectrum, the value of PV under PG\&E’s A-1 and A-6 rates is largely unaffected by PV penetration 
level. Second, the width of the percentile bands differs greatly across rates, indicating that the specific shape of the customer's load and/or PV production profile at each site has a much more significant impact on the value of PV for some rates than for others. For example, at a $2 \% \mathrm{PV}$ penetration level, the range between the $10^{\text {th }}$ and $90^{\text {th }}$ percentile values on LADWP's A-2, A rate is greater than $\$ 0.07 / \mathrm{kWh}$. In contrast, the value of PV on PG\&E’s A-1 and A-6 rates exhibits almost no variation across customers.

\subsection{Demand Charge Savings}

Both of the above observations are associated with differences across rates in the portion of the utility bill associated with demand charges. Figure 2 presents the value of PV when normalized to account for differences in the overall average cost of electricity on each rate. Thus, differences in the normalized value of PV between rates solely reflect differences in rate structure (i.e., how the overall bill is allocated between energy and demand charges and the structure of those charges). ${ }^{7}$ Figure 2 also shows a parameter called the demand weight, which represents the percentage of the total utility bill (pre-PV) allocated to demand charges (as opposed to volumetric energy charges). The demand weight ranges from $0 \%$ for PG\&E's A-1 and A-6, which have no demand charges, to approximately 50\% for LADWP's rates, for which demand charges comprise $50 \%$ of the total utility bill in the median case.

The figure shows that, when PV systems represent a small proportion of customer load, the existence of demand charges need not substantially degrade the rate-reduction value of PV. 
This is shown by the fact that, at $2 \%$ PV penetration, the normalized value of PV does not universally drop with increasing demand weight. In contrast, the decline in the median value of PV when PV penetration increases from 2\% to $75 \% \mathrm{PV}$ is clearly the greatest for those rates with the highest demand weight. The underlying reason for this trend is that, as PV system size is increased to meet a larger fraction of building load, the customer's peak demand shifts to periods when the PV system produces little or no output. As a result, those rates that are more heavily focused on demand charges yield lower bill savings at high PV penetration levels compared to rates that are less focused on demand charges.

The error bars in Figure 2 further demonstrate that the variation in the value of PV across customers increases with demand weight at both low and high PV penetration. As we show later, this trend reflects the fact that demand charge savings are highly sensitive to customer load shape. Thus, for those rates that are more focused on demand charges, the variability in the value of PV across customers is greater than for rates that are less focused on demand charges. 


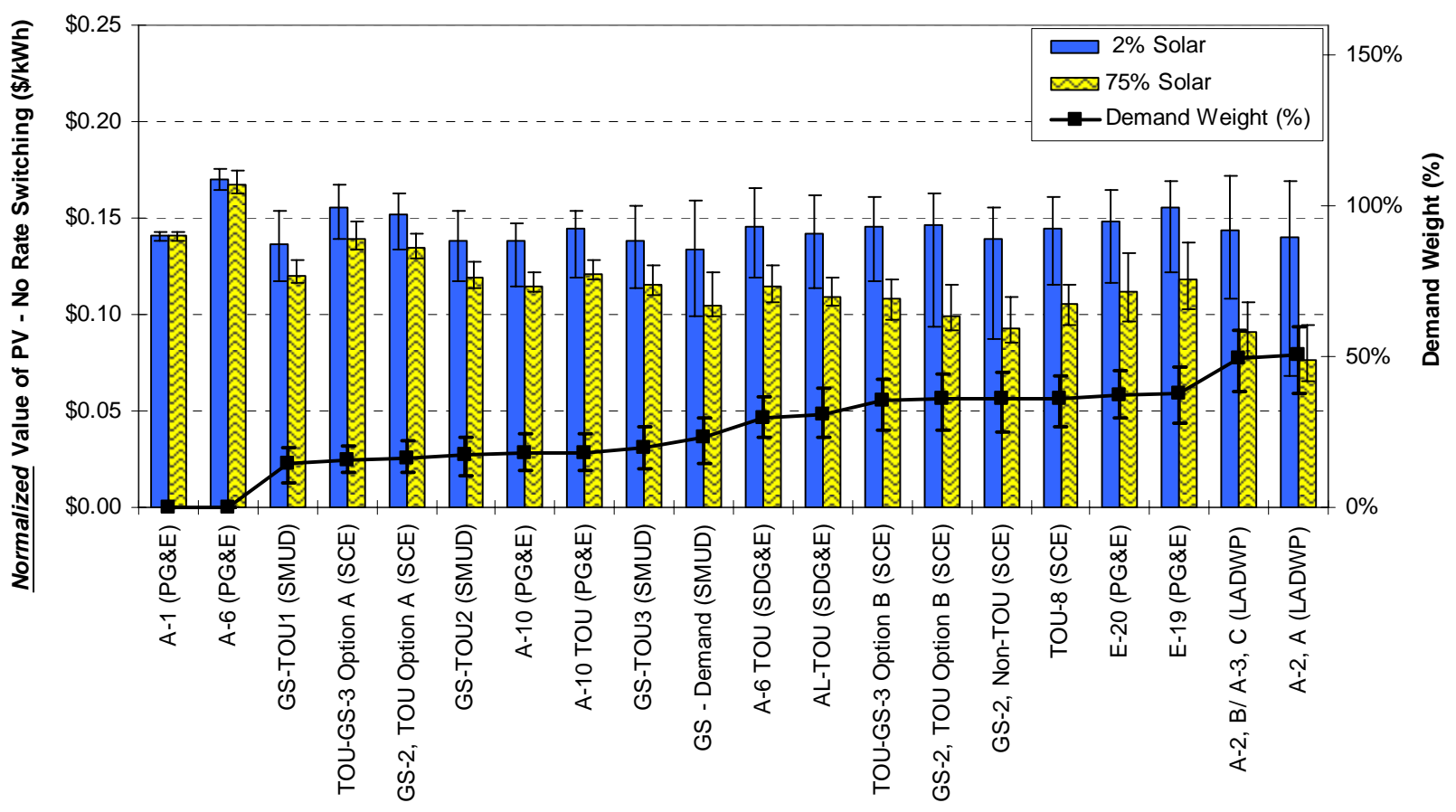

Median value with error bars for $10^{\text {th }}$ to $90^{\text {th }}$ percentile range

Figure 2. Impact of Demand Charges on the Overall Normalized Value of PV

\subsubsection{Demand charge design}

Rates can be differentiated not just in terms of the size of the demand charge, but also in terms of the type of demand charge. Among the rate schedules examined in this article, three different measures of customer demand are used as the basis for the demand charges: annual (maximum demand over the preceding 12 months), monthly (maximum demand in the monthly billing period), and time-of-day (maximum demand in one or more time-of-day periods within the monthly billing period). ${ }^{8}$ Figures 3 , 4 and 5 show the reduction in annual, monthly, and summer peak time-of-day (TOD) customer demand, respectively, across a range of PV penetration levels. The demand reductions are expressed in terms of effective capacity, defined as the reduction in peak customer load as a percentage of the 
maximum output of the PV system (e.g., a $100 \mathrm{~kW}$ PV system that reduces peak customer load by $25 \mathrm{~kW}$ would correspond to an effective capacity of 25\%). As in previous figures, the central tick-marks represent the median value across the 24 load/PV datasets and the error bands represent the $10^{\text {th }} / 90^{\text {th }}$ percentile values.

In all three figures, effective capacity declines steadily with increasing PV penetration, for reasons discussed earlier. That said we do find that peak demand reductions can be greater and much less variable across customers when demand charges are based on the customer's maximum demand during the summer peak TOD period, rather than the customer's annual or monthly peak demand. The extent to which this is true, however, depends very much on the particular definition of the summer peak TOD period that is used. This can be seen by comparing the summer peak TOD demand reductions under LADWP's and SMUD's definitions of the summer peak period. In particular, because SMUD's peak period extends into evening hours, it is more likely that the customer's peak demand will occur in hours when its PV system is producing little or no energy, and the effective capacity of PV in SMUD's territory is therefore lower and more variable than in LADWP's. 


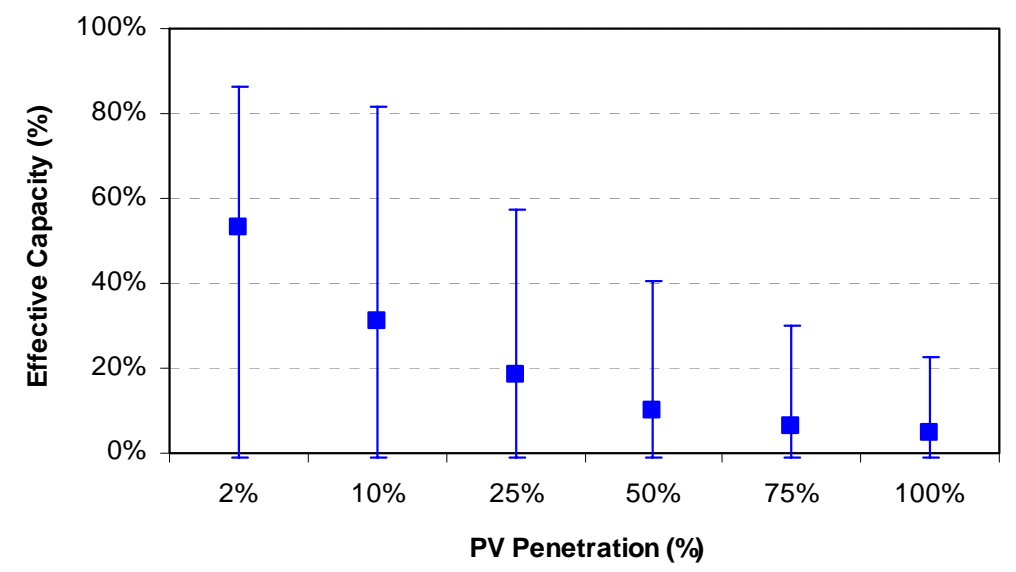

Median value with error bars for $10^{\text {th }}$ to $90^{\text {th }}$ percentile range

Figure 3. Effective Capacity of PV Systems: Annual Peak Reduction

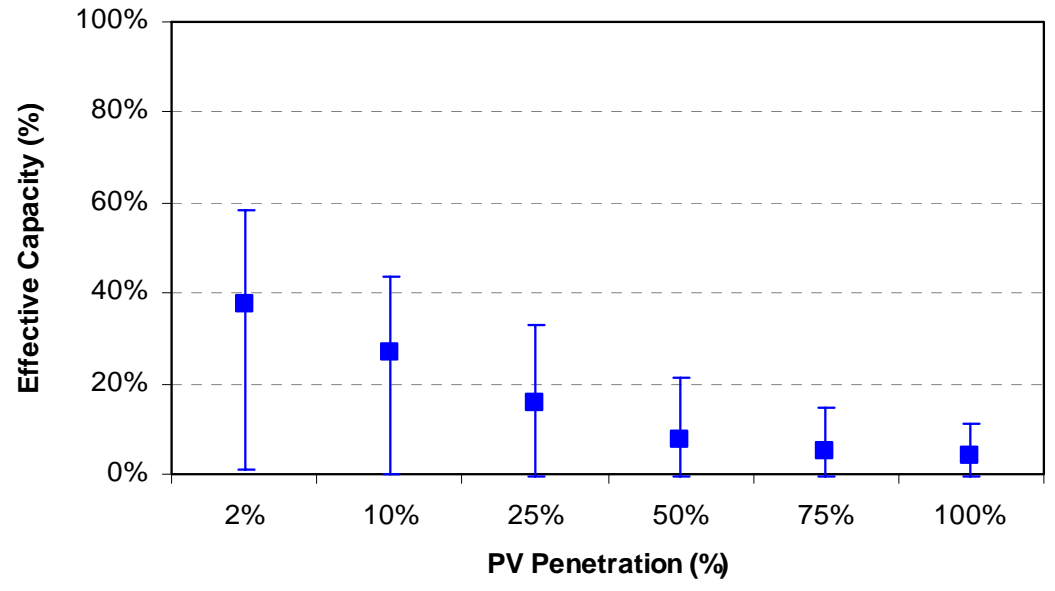

Median value with error bars for $10^{\text {th }}$ to $90^{\text {th }}$ percentile range

Figure 4. Effective Capacity of PV Systems: Average Monthly Peak Reduction 


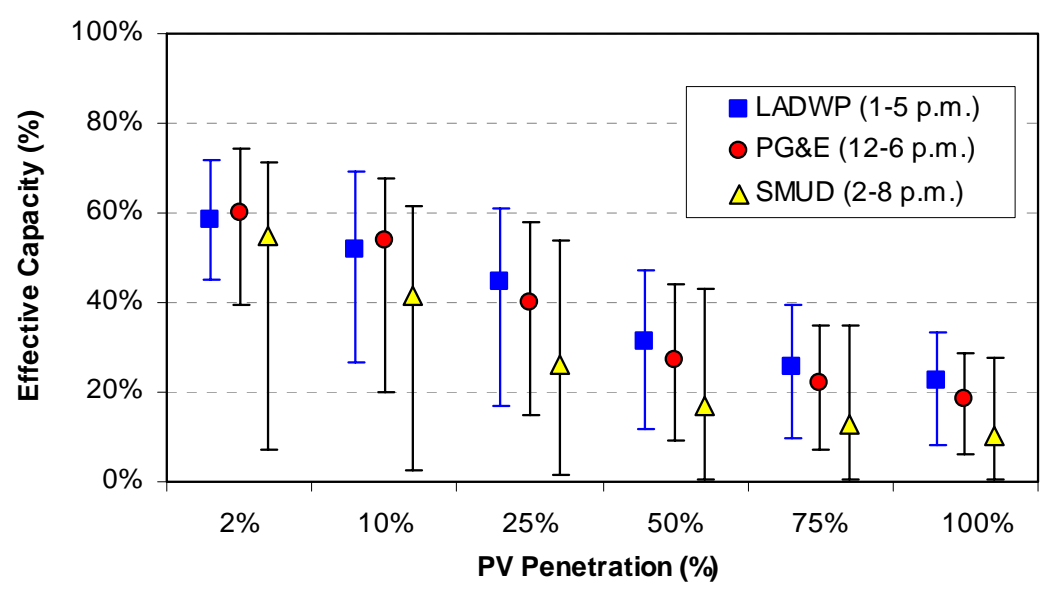

Median value with error bars for $10^{\text {th }}$ to $90^{\text {th }}$ percentile range

Figure 5. Effective Capacity of PV Systems: Average Monthly Summer Peak Period Reduction

\subsubsection{Customer load profile}

As previously shown, demand charge savings vary substantially across customers, indicating that the specific characteristics of the customer's building load profile and/or PV production profile can be important determinants of the rate-reduction value of PV.

Though not shown here, we find that differences in the PV production profile across the 24 customers in our sample have a very modest impact on demand charge savings (less than $\$ 0.01 / \mathrm{kWh}$ ). Variations in demand charge savings across customers is therefore almost entirely due to differences in customer load profiles.

To show how specific differences in customer load shape affect demand charge savings, Figure 6 presents the distribution in the normalized value of demand charge savings (median and 10th/90th percentiles) across the 18 rates with demand charges, for five 
representative customers: one with an inverted load profile (i.e., the peaks during nighttime hours), one with a flat profile, and three customers with load profiles that peak during afternoon hours. To illustrate the interrelationship between customer load shape and demand charge structure, we have segmented the 18 retail rates into two groups: those that contain TOD demand charges (shown on the right) and those that that do not (shown on the left).

We find that, regardless of the design of the demand charges, customers with an afternoon peak load shape can earn substantial demand charge savings at low PV penetration levels, and modest demand charge savings at high PV penetration levels. In contrast, customers with flat or inverted load profiles may receive, at most, modest demand charge savings, but only on rates with TOD charges and at low PV penetration levels. Clearly, the demand charge savings provided by PV will be highly customer specific.

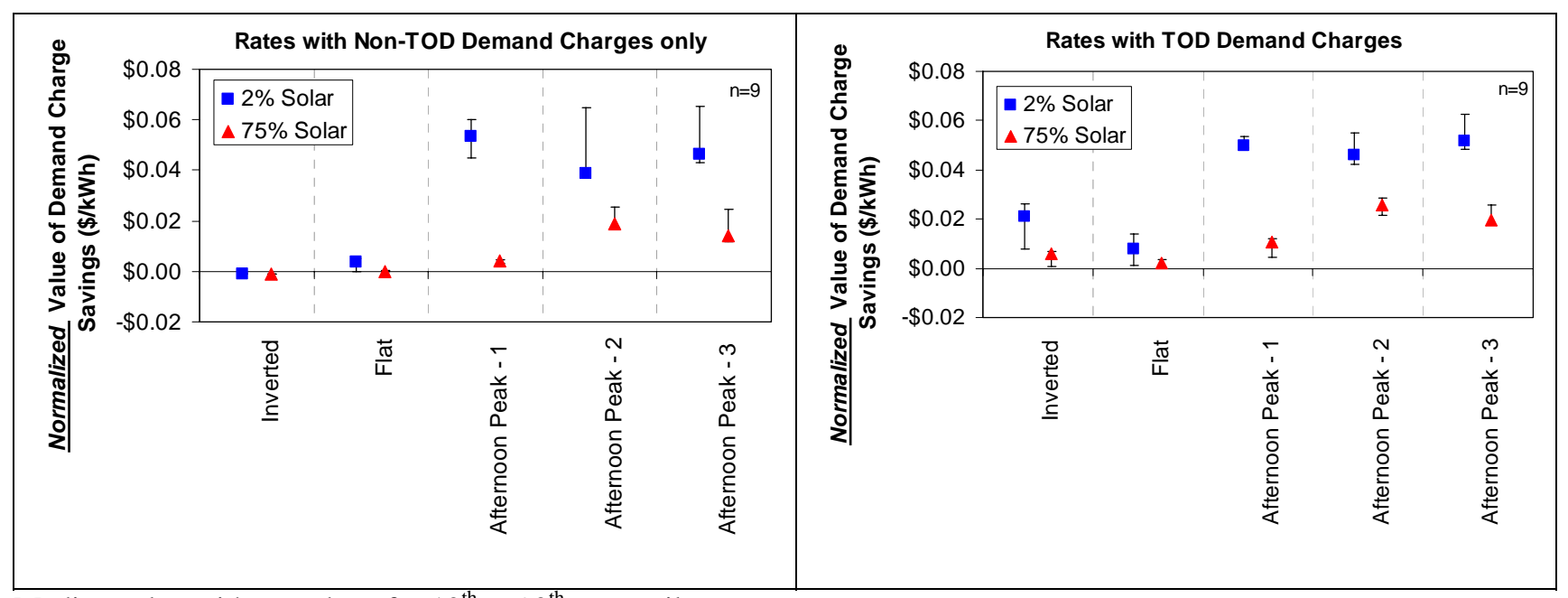

Median value with error bars for $10^{\text {th }}$ to $90^{\text {th }}$ percentile range

Figure 6. Normalized Demand Charge Savings for Different Load Shapes 


\subsection{Energy Charge Savings}

Just as the design of demand charges affects the rate-reduction value of PV, so too does the design of volumetric energy charges. Three different types of energy charges are represented among the rates examined in our analysis: one has an energy charge based on a single, flat rate for all kWh consumed, four have seasonal energy charges (i.e., a flat rate during winter months and a higher flat rate during summer months), and the remaining rates all have time-of-use (TOU) based energy charges. The TOU rates can be further distinguished according to the spread between peak and off-peak prices: for example, on some TOU rates, summer peak period prices are three-to-four times higher than winter offpeak prices, while on other TOU rates, peak prices are not even double the off-peak rates.

To illustrate how the value of PV in providing energy charge savings is affected by these differences in rate design, Figure 7 presents the normalized value of energy charge savings for each rate, grouping those rates according to the type of energy charge used and listing the rates in order of increasing summer peak to winter off-peak price ratio. As the figure indicates, TOU-based energy rates with relatively little spread between peak and off-peak prices offer approximately 5-10\% greater energy charge savings than do rates with seasonal or flat energy charges, whereas those TOU rates with a much larger price spread can offer more than $20 \%$ greater savings on energy charges than do flat or seasonal charges. The underlying reason for these findings is well understood: TOU rates provide a higher credit for PV production during summer afternoon periods, when production also tends to be greatest. 
The figure also shows that, in contrast to demand charge savings, energy charge savings are fairly consistent across customers, for any given rate. This is because the energy charge savings received for PV production under net metering are independent of the customer's load at any given time. As a result, predicting the energy charge savings of PV is relatively straightforward compared to estimating demand charge savings.

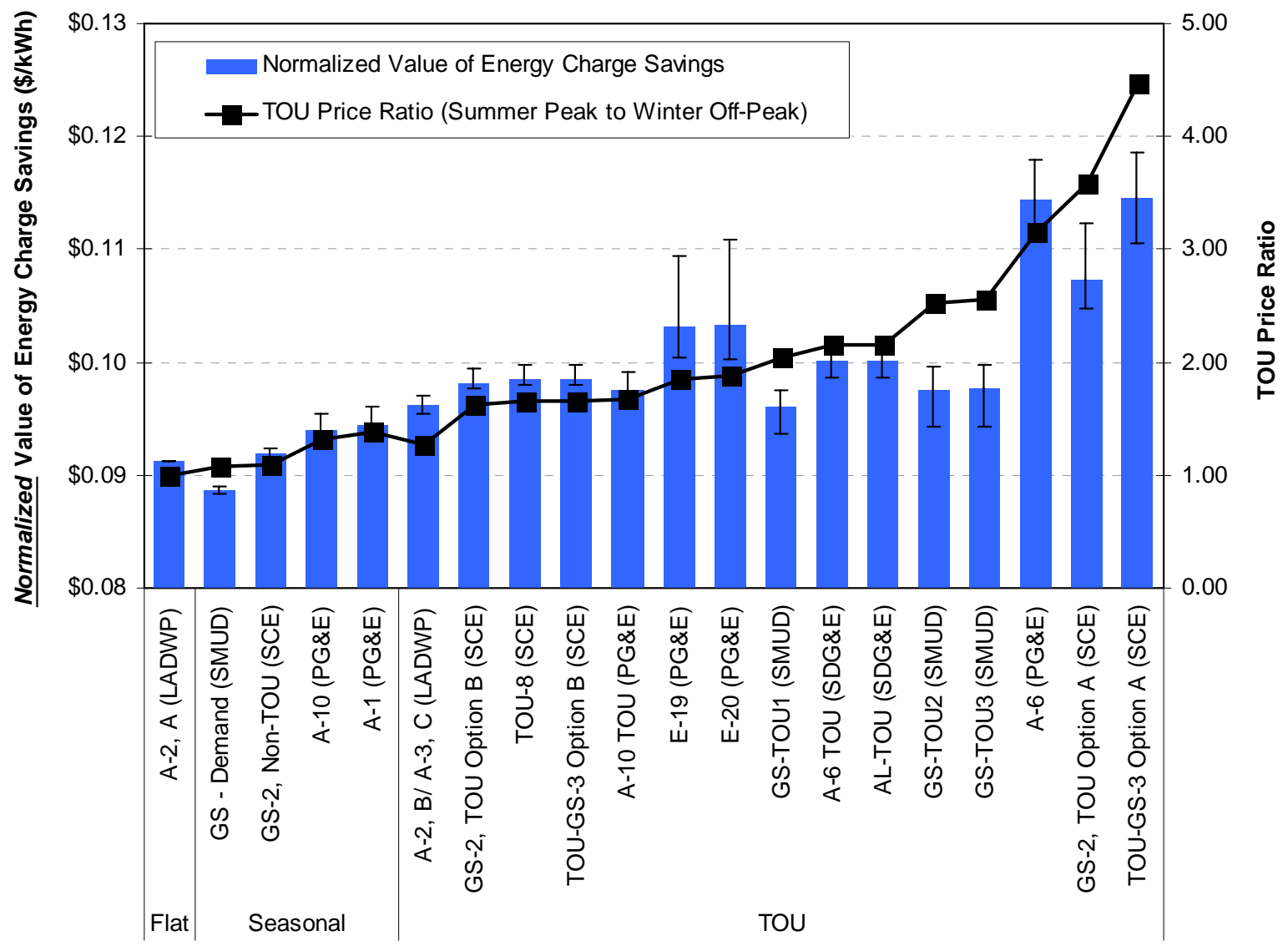

Median value with error bars for $10^{\text {th }}$ to $90^{\text {th }}$ percentile range

Figure 7. Summary of Rate Structure Impacts on Energy Charge Savings 


\subsection{Summary of PV Value Drivers}

To compare the relative impact of each of the various factors discussed above, we fit a linear regression model to the value of PV across all customer-rate combinations. The model includes five independent variables:

- the median cost of electricity for each rate across the 24 customers (pre-PV);

- the median demand weight for each rate;

- the median percentage of demand charges that are summer-peak TOD-based for each rate;

- the ratio of summer peak to winter off-peak energy charges for each rate; and

- a load shape parameter that characterizes the degree to which a customer's load profile is summer-peaking. ${ }^{9}$

The resulting regression model, at both $2 \%$ and $75 \%$ PV penetration, is presented in Table 2. ${ }^{10}$ As shown, the five variables included in the model are all statistically significant at a greater-than 95\% confidence level, are of the expected sign, and explain the majority of the variation in the rate-reduction value of PV. 
Table 2. Multiple Linear Regression Model of the Rate-Reduction Value of Commercial PV

\begin{tabular}{|c|c|c|c|c|c|}
\hline \multirow[b]{2}{*}{ Coefficient of Determination ( $R$ squared $)[a]$} & & \multicolumn{2}{|c|}{ 2\% Penetration } & \multicolumn{2}{|c|}{ 75\% Penetration } \\
\hline & & \multicolumn{2}{|r|}{0.734} & \multicolumn{2}{|r|}{0.903} \\
\hline Term & Input Range $[c]$ & Parameter & Significance (\%) $[\mathrm{b}]$ & Parameter & Significance (\%) \\
\hline Median Cost of Electricity $(\$ / \mathrm{kWh})$ & $0.0953 \rightarrow 0.1616$ & 1.149 & $>99.99 \%$ & 1.001 & $>99.99 \%$ \\
\hline Median Demand Weight & $0.0 \rightarrow 0.504$ & -0.020 & $99.20 \%$ & -0.104 & $>99.99 \%$ \\
\hline TOU Price Spread & $1.0 \rightarrow 4.467$ & 0.006 & $>99.99 \%$ & 0.006 & $>99.99 \%$ \\
\hline Median Portion of Demand from Summer Peak TOD Charges & $0.0 \rightarrow 0.465$ & 0.011 & $98.10 \%$ & 0.006 & $>99.99 \%$ \\
\hline Load Shape & $0.5871 \rightarrow 1.9097$ & 0.027 & $>99.99 \%$ & 0.014 & $>99.99 \%$ \\
\hline Intercept (\$/kWh) & & -0.054 & $>99.99 \%$ & -0.020 & $>99.99 \%$ \\
\hline
\end{tabular}

[a] The coefficient of determination describes how well the model is able to account for variations in the Value of PV; 1.0 being a perfect model.

[b] The significance indicates the probability that a particular parameter is different than zero

[c] The input range is the distance between the data point that gives the lowest and highest value of PV for each variable

The parameters of the regression model can also be used to determine the expected change in the rate-reduction value of PV based on the maximum range of each of the independent variables for the 20 rates and 24 customers. The results of that calculation are shown in Figure 8.

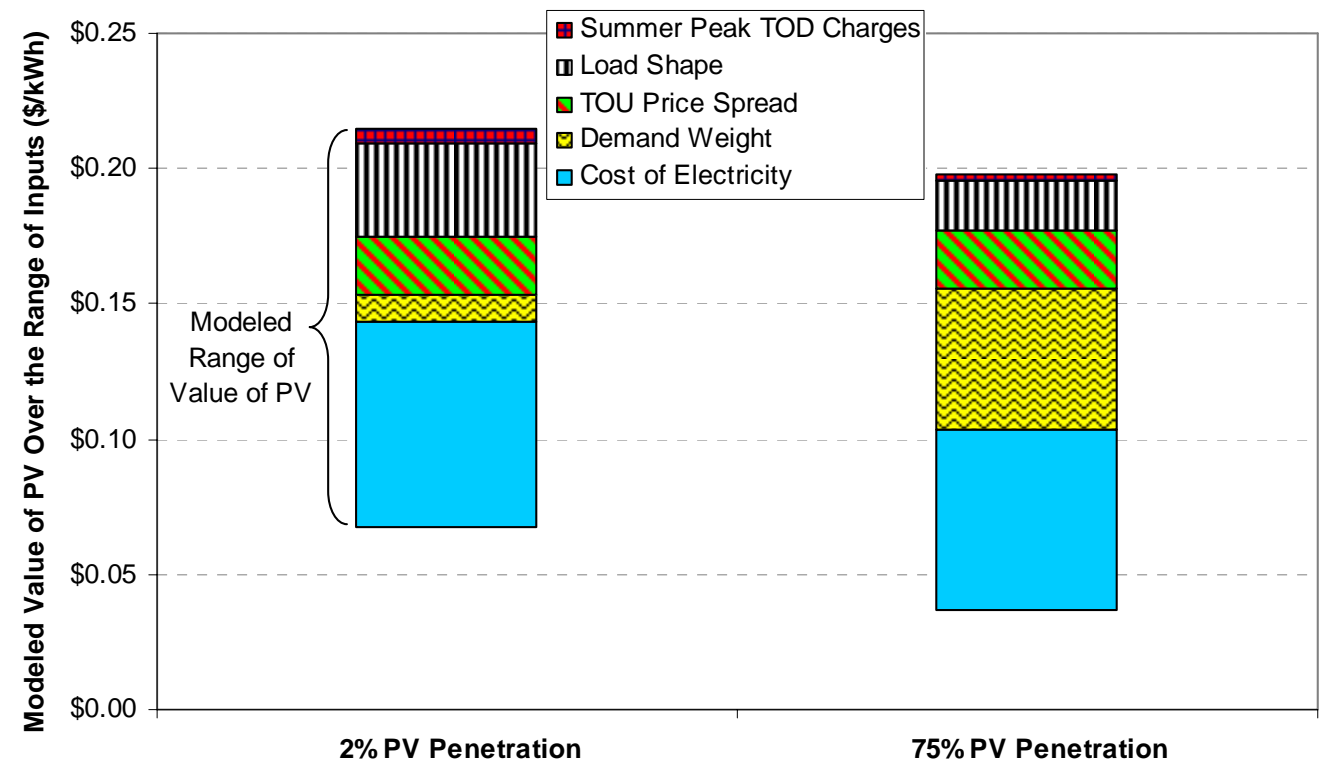

Figure 8. Modeled Change in the Value of PV Based on the Range of Each Factor 
The height of each bar-segment in Figure 8 reflects the (modeled) difference in the value of PV across the full range of possible values for each variable, based on the regression model parameters shown in Table 2. The bar-segments are stacked beginning with the lowest value of PV calculated using the extremes of each independent variable. The highest value of PV at the top of the stack is then the value of PV calculated from the opposite extreme of variable values.

As Figure 8 shows, the largest driver for the rate-reduction value of PV, regardless of PV penetration level, is the median cost of electricity on the rate (for customers without PV). The coefficient value of roughly one indicates that every $\$ 0.01 / \mathrm{kWh}$ increase in the median cost of electricity will, on average, yield an increase of the rate-reduction value of PV of a similar magnitude. At a 75\% PV penetration level, the next most important factor is the demand weight. As demonstrated earlier, at high levels of PV penetration, retail rates with high demand charges almost always lead to lower values of PV compared to rates with lower demand charges. At a 2\% PV penetration level, meanwhile, the second mostimportant factor, after the median cost of electricity, is the customer load shape. The positive parameter estimate for this variable shows that, in general, the more energy a customer consumes during the summer peak period, the greater the value of PV. As discussed earlier, this is largely because PV systems are better able to offset demand charges for customers with summer-afternoon peaking loads that coincide with periods of high PV output. At higher levels of PV penetration, the ability of PV systems to reduce 
demand charges is diminished regardless of customer load shape, and thus the magnitude of the load shape parameter is lower at $75 \%$ penetration than at $2 \%$ penetration.

To conclude, this analysis shows that the value of PV will generally be greatest for rates with high overall costs of electricity, small or non-existent demand charges, high summer peak to winter off-peak energy price spreads, and demand charges that are based on customer load during the summer peak period. In general, if demand charges are assessed the value of PV will be greater for those customers that consume a disproportionately high amount of energy during the summer peak period.

\section{Optimal Rate Selection}

The analysis presented thus far assumes that customers are on the same retail electricity rate before and after PV installation. In reality, however, customers in California and other jurisdictions often have a choice of rate options, and can select the rate that minimizes their bill. In this section, we therefore assume that customers choose among the available retail rates both before and after PV installation, and that in both cases customers select the rate that will minimize their electric bill.

Using this alternative analytic technique, we find that, at low levels of PV penetration, customer load characteristics largely determine the optimal retail rate, and that the existence of a PV system does not lead to widespread rate switching from the before-PV case. Said differently, we find that the optimal rate post-PV is generally the same as the 
optimal rate pre-PV, and that the optimal rate is determined by the characteristics of the customer's load profile, and not the existence of the PV system.

At higher levels of PV penetration, however, a substantial proportion of customers are found to be better off switching to an energy-focused "PV-friendly" rate that minimizes demand charges. As PV system size increases relative to customer load, the customer's load profile is dominated by the existence of the PV system in optimal rate selection.

To illustrate this result, we categorize three of the retail rates in our sample as being "PVfriendly” primarily due to minimal or no demand charges: PG\&E’s A-6; SCE’s GS-2, TOU Option A; and SCE’s TOU-GS-3 Option A. ${ }^{11}$ Depending on its peak demand, a customer may be able to choose between one of these "PV-friendly" rates and one or more other rate options, as shown in Table 3. For each of the 24 customers in our dataset, we determined the optimal rate within each of the four rate groups identified in Table 3, across a range of PV penetration levels.

Table 3. Rate Options for Different Customer Classes

\begin{tabular}{|c|c|c|}
\hline \multicolumn{3}{|c|}{ Rate Options } \\
\hline Utility & Customer Size & Rate Options Available \\
\hline \multirow{4}{*}{ PG\&E } & \multirow{2}{*}{$<200 \mathrm{~kW}$} & PV-friendly: A-6 \\
\hline & & Other Rates: A-1; A-10; A-10 TOU; and E-19 \\
\hline & \multirow{2}{*}{$200-500 \mathrm{~kW}$} & PV-friendly: A-6 \\
\hline & & Other Rates: A-10 TOU and E-19 \\
\hline \multirow{4}{*}{ SCE } & \multirow{2}{*}{$20-200 \mathrm{~kW}$} & PV-friendly: GS-2, TOU Option A \\
\hline & & Other Rates: GS-2, TOU Option B and GS-2, Non-TOU \\
\hline & \multirow{2}{*}{$200-500 \mathrm{~kW}$} & PV-friendly: TOU-GS-3 Option A \\
\hline & & Other Rates: TOU-GS-3 Option B \\
\hline
\end{tabular}


Figure 9 shows the resulting percentage of customers for which each "PV-friendly" rate is optimal, compared to the other rates available to the same class of customers. At PV penetration levels greater than $50 \%$, all or nearly all of the customers in our sample would minimize their utility bill by switching to an available energy-focused "PV-friendly" rate that minimizes demand charges. At low PV penetration levels (e.g., 10\%), however, these "PV-friendly" tariffs would not be optimal for many customers, as the least-cost rate will largely depend on the characteristics of the customer's underlying load shape.

In summary, energy focused rates that minimize demand charges are of great value to commercial customers wishing to install relatively large PV systems. If energy-focused rates were required of all commercial PV systems, however, many customers wishing to install smaller PV systems (relative to load) would be disadvantaged. As a result, optional energy-focused retail rates will be most-supportive of commercial PV expansion.

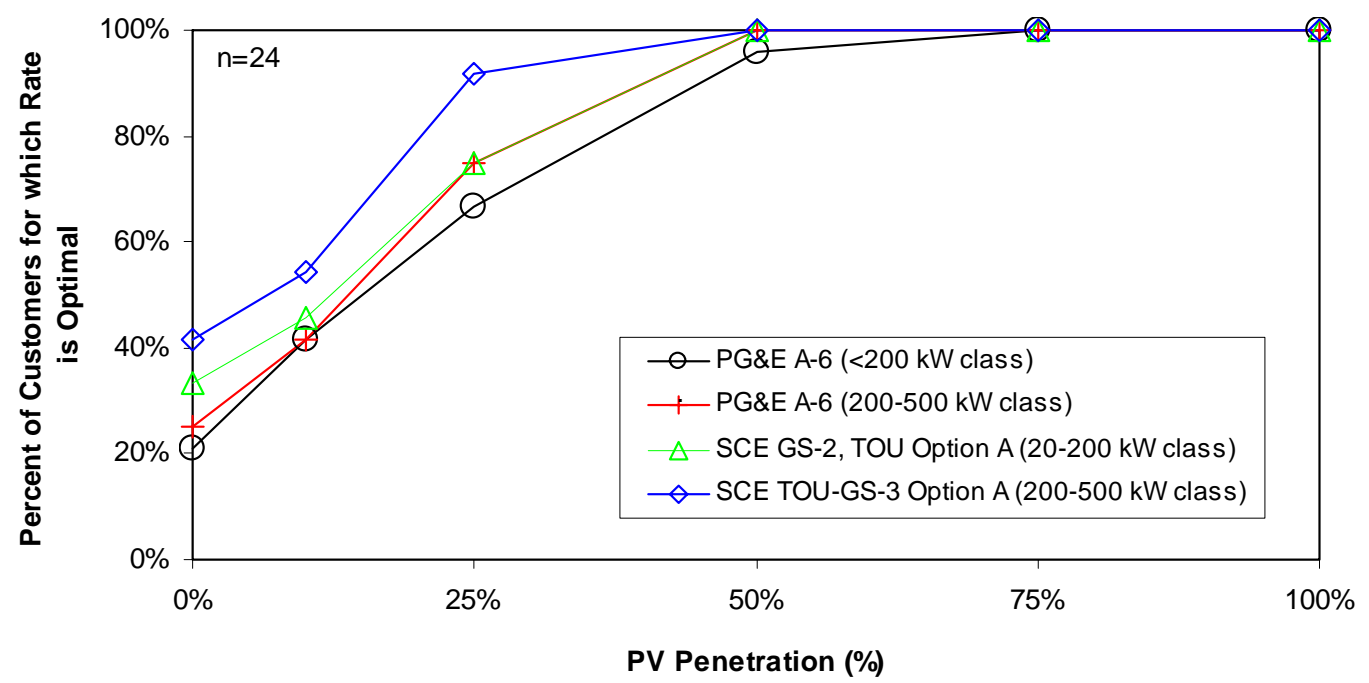

Figure 9. Customer Choice of Energy-Focused Rates at Varying Levels of PV Penetration 


\section{The Value of Net Metering}

The analysis presented thus far assumes that PV systems are net metered, as allowed under existing law in California. To assess the impact of net metering on the rate-reduction value commercial PV systems, we compare the value of PV for the various customer-rate combinations, as calculated previously, to the value of PV if net metering were not available. Doing so requires an assumption about how PV output would be compensated in the absence of net metering. For the purpose of our analysis, we assume that, without net metering, PV production in excess of the customer's load during any 15-minute interval would either be uncompensated (i.e., "donated" to the utility) or sold to the local electric utility at some pre-specified sell-back rate. Just as with net metering, all PV production up to the customer's load during each 15-minute interval is assumed to be valued at the prevailing retail rate; the only difference is in the treatment of excess PV production, above the customer’s load, during each 15-minute interval.

Figure 10 shows the loss in value that is expected were net metering to be eliminated, for all customer-rate combinations, across a range of PV penetration levels and under four different sell-back rates (including \$0.00/kWh, where excess generation in each 15 minute interval is donated to the utility). For each scenario, the central tick-marks in the figure show the median percentage reduction in bill savings, and the percentile bands show the $10^{\text {th }}$ and $90^{\text {th }}$ percentile values, across all combinations of rates and load/PV datasets. ${ }^{12}$ 


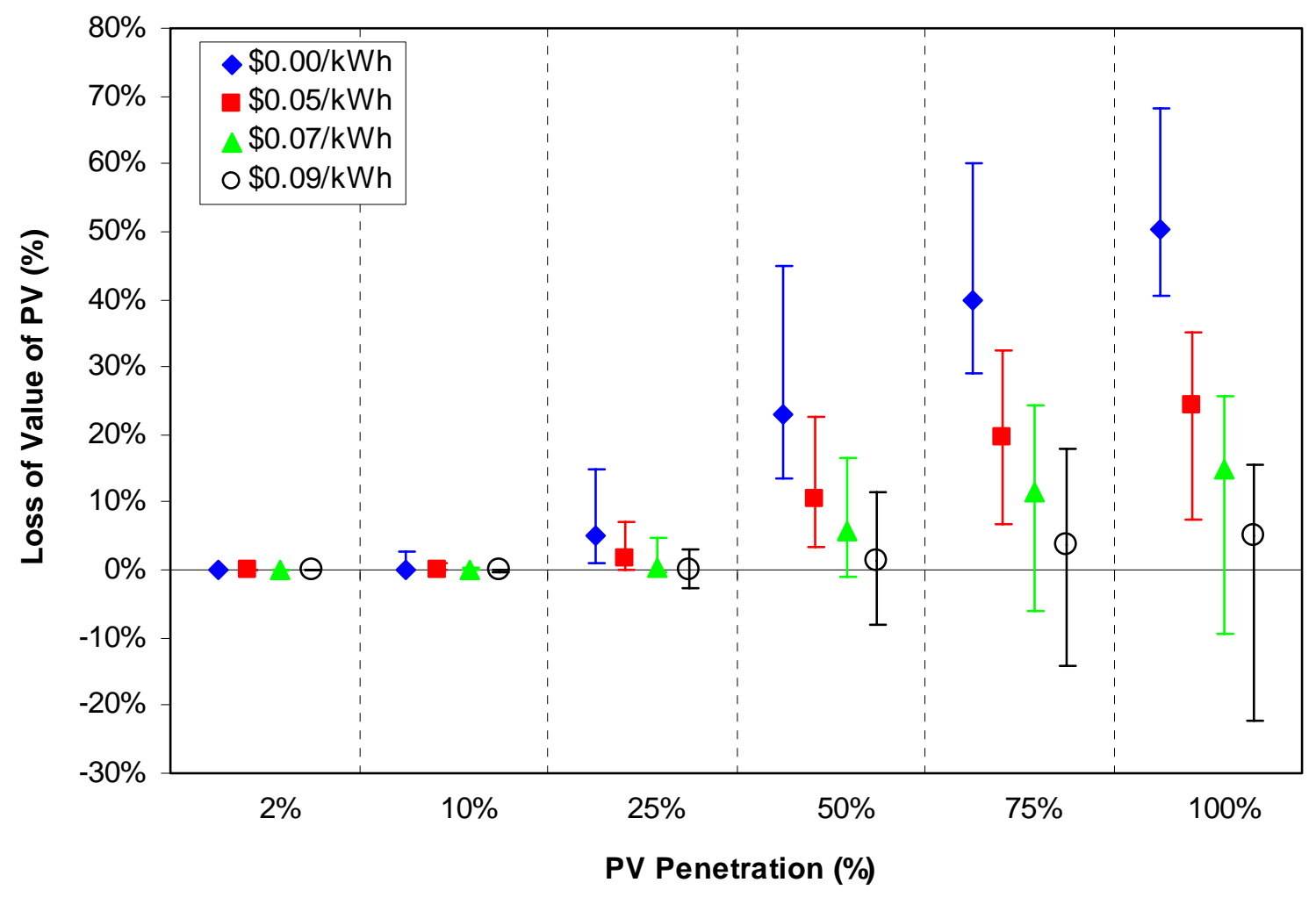

Figure 10. Loss of Value without Net Metering, Depending on the Sell-Back Rate for Net Excess Generation

As the figure shows, eliminating net metering could significantly degrade the economics of PV systems that serve a large percentage of building load, depending on the sell-back rate for excess PV output. For example, at a 75\% PV penetration level, eliminating net metering would reduce the value of PV by $10-30 \%$ for most customer-rate combinations, at a $\$ 0.05 / \mathrm{kWh}$ sell-back rate, and by $30-60 \%$ if excess PV output was uncompensated. At the same time, the figure also shows that, at low PV penetration levels, or at relatively high sell-back rates, net metering provides only a modest incremental value, compared to the alternate compensatory structure assumed in our analysis. For example, at PV penetration levels of $25 \%$ or less, or with a sell-back rate of $\$ 0.09 / \mathrm{kWh}$, replacing net metering with 
the alternative compensatory structure would reduce the value of PV by less than $10 \%$ for most customers.

\section{Conclusions}

The ultimate goal of government solar policy is to create a self-sustaining market for PV that is able to succeed with a minimum of ongoing government intervention. To do so, in the U.S. at least, where feed-in tariffs are not prevalent, PV will likely need to be competitive with retail electricity rates.

Though retail rate design is sometimes an overlooked element of solar policy, as we have shown, the specifics of the rate structure, combined with the characteristics of the customer's underlying load and the size of the PV system, can have a substantial impact on the economics of customer-sited commercial PV. Though regulators must consider a number of sometimes-conflicting objectives when designing and approving retail rates, key conclusions for policymakers that emerge from our analysis include the following:

- $\quad$ Rate design is fundamental to the economics of customer-sited, commercial PV. The rate-reduction value of PV for our sample of commercial customers, considering all available retail tariffs in California, ranges from $\$ 0.05 / \mathrm{kWh}$ to $\$ 0.24 / \mathrm{kWh}$, reflecting differences in rate structures, the revenue requirements for each rate, the size of the PV system relative to building load, and customer load shapes. For the average customer in 
our sample, differences in rate structure, alone, alter the value of PV by $25 \%$ to $75 \%$, depending on the size of the PV system relative to building load.

- TOU-based energy-focused rates can provide substantial value to many PV customers. Retail rates that wrap all or most utility cost recovery needs into time-of-use (TOU)-based volumetric energy charges, and that exclude or limit demand-based charges, provide the most value to PV systems across a wide variety of circumstances. Expanding the availability of such rates would increase the value of many commercial PV systems.

- Offering commercial customers a variety of rate options would be of value to PV. Despite the advantages of energy-focused rates for PV, requiring the use of these tariffs would disadvantage some commercial PV installations. In particular, for PV systems that serve a relatively small percentage of annual customer load, the characteristics of the customer's underlying load profile will typically determine the most favorable rate structure, and energy-focused rate structures may not be ideal for many commercialcustomer load shapes. Regulators that wish to establish rates that are beneficial to a range of PV applications may therefore wish to consider allowing customers to choose from among a number of different rate structures.

- $\quad$ Net metering is quite valuable to commercial PV installations that serve a large percentage of building load. Under the assumptions stipulated in this article, we find that an elimination of net metering could, in some circumstances, result in more than a $25 \%$ loss in the rate-reduction value of commercial PV. As long as annual solar output is less than 
roughly $25 \%$ of customer load and excess PV production can be sold to the local utility at a rate above $\$ 0.05 / \mathrm{kWh}$, however, elimination of net metering is found to rarely result in a financial loss of greater than $5 \%$ of the rate-reduction value of PV.

More detailed conclusions on the rate-reduction value of commercial PV include:

- Commercial PV systems can sometimes greatly reduce demand charges. Though energy-focused retail rates often offer the greatest rate reduction value, commercial PV installations can generate significant reductions in demand charges as well, in some cases constituting $10-50 \%$ of the total rate savings derived from PV installations.

- The value of demand charge reductions declines with PV system size. At high levels of PV penetration, the value of PV-induced demand charge savings on a $\$ / \mathrm{kWh}$ basis can drop substantially. As a result, the rate-reduction value of PV can decline by up to onehalf when a PV system meets $75 \%$ rather than $2 \%$ of total building load.

- The ability of PV to offset demand charges is highly customer-specific. Customers with loads that peak in the afternoon are often able to receive significant demand charge savings across a wide variety of circumstances, at least at lower levels of PV output relative to building load. In contrast, facilities with flat or inverted load profiles will often not earn much demand charge reduction value, regardless of PV system size. 
- $\quad$ The type of demand charge can impact the ability of PV to offer savings. TODbased demand charges are found to be more favorable to PV under a broad range of customer load shapes than are those based on monthly or annual peak customer demand.

- $\quad$ The type and design of energy-charges has an important impact on PV value. TOUbased energy charges with a high spread between peak and off-peak prices are found to offer greater value to commercial PV in California than rates with seasonal or flat energy charges.

Though our detailed findings are specific to California, the general conclusions presented above will also be of use in other jurisdictions that are seeking to encourage customer-sited commercial PV installations. Ultimately, our most important finding is simply that choices made by policymakers in establishing or revising retail electricity rates can have a profound impact on the viability of customer-sited solar markets. We hope that the analysis presented in this article serves as a useful step in illuminating some of the aspects of rate design that are of particular salience, and will also assist PV retailers and customers better asses the value proposition of commercial PV systems.

\section{Acknowledgements}

The work described in this article was funded by the National Renewable Energy Laboratory under Memorandum Purchase Order No. DEK-6-66278-01, and by the U.S. Department of Energy (Office of Electricity Delivery and Energy Reliability, Permitting, Siting and Analysis) under Contract No. DE-AC02-05CH11231. We would particularly 
like to thank Robert Margolis (National Renewable Energy Laboratory) and Larry

Mansueti (United States Department of Energy) for their support of this work. We also

thank Tom Kimbis, Craig Cornelius and Charles Hemmeline, all of the U.S. DOE's Solar

Program. We appreciate the willingness of several firms to provide the data necessary for this project: Fat Spaniel, SPG Solar, PowerLight, and Chevron Energy Solutions.

\section{References}

Bhattacharjee, U. and J. Duffy. 2006. "Effect of PV on Reducing Demand Charges: Case Study of a 26 kW PV System in MA.” Proceedings: Solar 2006. Denver, Colorado.

Bolinger, M. and R. Wiser. 2002. "Customer-Sited PV: A Survey of Clean Energy Fund Support.” LBNL-49668. Berkeley, California: Lawrence Berkeley National Laboratory.

Bonbright, J. 1961. Principles of Public Utility Rates. Public Utilities Reports, Inc. New York: Columbia University Press.

Borenstein, S. 2005. "Valuing the Time-varying Electricity Production of Solar Photovoltaic Cells.” Center for the Study of Energy Markets, Working Paper 142. Berkeley, California: U.C. Energy Institute.

Cooper, C. and J. Rose. 2006. "Freeing the Grid: How Effective State Net Metering Laws Can Revolutionalize U.S. Energy Policy.” Report No. 01-06. Network for New Energy Choices.

Duke, R., Williams, R. and A. Payne. 2005. "Accelerating Residential PV Expansion: Demand Analysis for Competitive Electricity Markets.” Energy Policy, 33 (15): 1912-1929.

Energy \& Environmental Economics, Inc. (E3). 2006. "Renewable Distributed Generation Assessment: San Francisco Public Utilities Commission/Hetch Hetchy Case Study.” CEC-500-2006-002. Sacramento, California: California Energy Commission.

Energy \& Environmental Economics, Inc. (E3). 2005a. "Renewable Distributed Generation Assessment: City of Palo Alto Utilities Case Study.” CEC-500-2005-029. Sacramento, California: California Energy Commission. 
Energy \& Environmental Economics, Inc. (E3). 2005b. "Renewable Distributed Generation Assessment: Sacramento Municipal Utility District Case Study.” CEC-500-2005028. Sacramento, California: California Energy Commission.

Energy \& Environmental Economics, Inc. (E3). 2005c. "Renewable Distributed Generation Assessment: Alameda Power and Telecom Case Study.” CEC-500-2005-010. Sacramento, California: California Energy Commission.

Firestone, R. Marnay, C. and K. Maribu. 2006. "The Value of Distributed Generation under Different Tariff Structures.” Proceedings: 2006 ACEEE Summer Study on Energy Efficiency in Buildings. Pacific Grove, California: American Council for an Energy-Efficient Economy.

Herig, C. and T. Starrs. 2002. "Restructuring and Ratemaking: Implications for Distributed PV Applications.” Proceedings: Solar 2002 Conference. Reno, Nevada.

Hoff, T. 1998. “Using Distributed Resources to Manage Risks Caused by Demand Uncertainty.” The Energy Journal, special issue: 63-83.

Hoff, T. 1996 “Identifying Distributed Generation and Demand Side Management Investment Opportunities.” The Energy Journal, 17(4): 89-105.

Hoff, T. and R. Margolis. 2004. “Are Photovoltaic Systems Worth More to Residential Consumers on Net Metered Time-of-Use Rates?” Proceedings: Solar 2004 Conference. Portland, Oregon.

Hoff, T., Norris, B. and G. Wayne. 2003. "Potential Economic Benefits of Distributed Photovoltaics to the Nevada Power Company.” Prepared for Nevada Power Corporation.

Hoff, T., Wenger, H. and B. Farmer. 1996. "Distributed Generation: An Alternative to Electric Utility Investments in System Capacity.” Energy Policy, 24(2): 137-147

Hoff, T., Wenger, H. and D. Keane. 1992. "Evaluating the Revenue Impacts of CustomerSited Renewable Generation Using Load Research Data.” Proceedings: Western Load Research Association Fall Meeting. San Francisco, California.

Hughes, L. and J. Bell. 2004. "Compensating Customer-Generators: A Taxonomy Describing Methods of Compensating Customer-Generators for Electricity Supplied to the Grid.” Energy Policy, 34: 1532-1539.

Johnston, L., Takahashi, K., Weston, F. and C. Murray. 2005. "Rate Structures for Customers with Onsite Generation: Practice and Innovation.” NREL/SR-56039142. Golden, Colorado: National Renewable Energy Laboratory. 
Lambeth, R. and T. Lepley. 1993. "Distributed photovoltaic system evaluation by Arizona Public Service Company.” Proceedings: 23rd IEEE Photovoltaic Specialists Conference. Louisville, Kentucky.

Letendre, S., Perez, R. and C. Herig. 2001. "An Assessment of Photovoltaic Energy Availability During Periods of Peak Power Prices.” Proceedings: ASES Annual Conference and Proceedings of the 26th National Passive Solar Conference. Washington, D.C.

Maine, T. and P. Chapman. 2007. "The Value of Solar: Prices and Output from Distributed Photovoltaic Generation in South Australia.” Energy Policy, 35: 461-466.

Perez, R., Margolis, R., Kmiecik, M., Schwab, M. and M. Perez. 2006. "Effective LoadCarrying Capability of Photovoltaics in the United States.” Proceedings: Solar 2006. Denver, Colorado.

Perez., R. Letendre, S. and C. Herig. 2001. "PV and Grid Reliability: Availability of PV Power During Capacity Shortfalls.” Proceedings: ASES Annual Conference and Proceedings of the 26th National Passive Solar Conference. Washington, D.C.

Perez, R., Seals, R. and C. Herig. 1997. "Determination of the End-Use Effective Capacity of PV.” Proceedings: 14th European PV Conference. Barcelona, Spain.

Perez, R., Seals, R. and R. Stewart. 1994. "Matching Utility Peak Loads with PV.” Proceedings: RENEW 94. Stamford, Connecticut.

Pop, M. 2005. "The Value of Distributed, Urban Residential Photovoltaic Electricity in the Australian National Electricity Market.” Center for Energy and Environmental Markets. University of New South Wales.

Rowlands, I. 2005. "Solar PV Electricity and Market Characteristics: Two Canadian Case Studies.” Renewable Energy, 30: 815-834.

Shugar, D., Orans, R., Jones, A., El-Gassier, M. and A. Suchard. 1992. "Benefits of Distributed Generation in PG\&E's Transmission and Distribution System: A Case Study of Photovoltaics Serving Kerman Substation.” San Francisco, California: Pacific Gas \& Electric Company.

Smeloff, E., Redlinger, R., Kelly and J. Baker. 2006. "Prepared Testimony of the Vote Solar Initiative.” Before the Public Utilities Commission of California. Docket A.05-05-023.

Wenger , H., Hoff, T. and J. Peppers. 1996. "Photovoltaic Economics and Markets: The Sacramento Municipal Utility District as a Case Study.” SMUD Contract G253, CEC Contract 500-94-030. Sacramento, California. 
Wenger, H., and T. Hoff. 1995. "The Value of Photovoltaics in the Distribution System: The Kerman Grid-Support Project.” Pacific Gas \& Electric Company and the U.S. Department of Energy. San Ramon, California.

\section{Weston, F., 2000. "Charging for Distribution Utility Services: Issues in Rate Design.” Montpelier, Vermont: Regulatory Assistance Project.}

Western Governors’ Association (WGA). 2006. “Clean and Diversified Energy Initiative: Solar Task Force Report.” Prepared from the Western Governors’ Association’s Clean and Diversified Energy Initiative.

\section{Wiser, R., Mills, A., Barbose, G., and W. Golove. 2007. “The Impact of Retail Rate Structures on the Economics of Commercial Photovoltaic Systems in California.” LBNL-63019. Berkeley, California: Lawrence Berkeley National Laboratory.}

\footnotetext{
${ }^{1}$ State and federal financial incentives, and sales of renewable energy certificates, represent other possible monetary gains.

${ }^{2}$ Literature that has focused on avoided variable costs in terms of the correlation between PV production and wholesale market prices includes Borenstein (2005); Rowlands (2005); Maine and Chapman (2007); and Letendre et al. (2001). Avoided fixed costs tend to be highly site-specific, and are often tied to the effective load carrying capacity of PV. Literature that has addressed the reliability or effective load carrying capacity of PV, on a system-wide basis, include Perez et al. (1994, 2001, 2006). Others who have sought to evaluate the benefits of PV in offsetting the fixed costs of transmission and distribution investments include: Wenger and Hoff (1995); Wenger et al. (1996); Lambeth and Lepley (1993); Hoff (1996, 1998); Hoff et al. (1996, 2003); Shugar et al. (1992); and E3 (2005a,b,c, 2006).

${ }^{3}$ The customer-based ELCC is a statistical estimate of the expected reduction in building load due to the production of power by an onsite PV system.

${ }^{4}$ Our analysis is based on utility tariff books, current as of January 2007. We assumed that customers connect to the electrical grid through poly-phase connections at unity power factor. For PG\&E, SCE, and SMUD, we assumed that customers connect at a secondary voltage level, while for SDG\&E and LADWP, we assumed that customers connect at a primary voltage level.

${ }^{5}$ Further details on each dataset can be found in Wiser et al. (2007).

${ }^{6}$ All datasets had greater than $96 \%$ data availability, where data availability is defined as the number of unmodified data points divided by the total number of data points available over the one year time period with 15-minute data recording intervals (as defined in IEC 61724, Section 7). Twenty of the 24 datasets (83\%) had $99 \%$ or greater data availability.

${ }^{7}$ To isolate the impact of differences in rate structure, the value of PV for each customer-rate combination can be normalized to control for differences in the magnitude of charges on each rate. We calculate the normalized value of PV by first dividing the value of PV for each customer-rate combination by the median cost of electricity on that rate across all 24 customers, prior to PV installation. We then multiply this value by the median cost of electricity across all combinations of the 24 customers and 20 rates (again without PV). It is important to note that it is the relative value of these normalized results that matters; the specific numerical values have no particular meaning.

${ }^{8}$ Time-of-day (TOD) demand charges typically focus on the summer weekday afternoon TOD period, but may also include lesser charges for other TOD periods.

${ }^{9}$ The load shape parameter is the ratio of the percent of total electricity demand during the summer peak period to the percent of time that is defined as summer peak for each utility. A value above one indicates that proportionally more energy is consumed during the summer peak period than during other periods of the year; a high value therefore corresponds to a facility with a large afternoon peak during the summer.
} 
${ }^{10}$ One limitation of this analysis is that the regression model involves the use of independent variables that are derived from the same set of data used to calculate the dependent variable, the value of PV. To minimize the chance of spurious relationships due to the use of the same data in calculating the dependent and independent variables we use median values calculated from the whole set of customers to characterize some of the general features of the 20 different retail rates.

${ }^{11}$ Though PG\&E's A-1 rate has no demand charges, it is not designated as "PV-friendly" in this report because other available rates are more attractive to all 24 of the customers in our sample, at all levels of PV penetration. LADWP similarly offers an otherwise "PV-friendly" rate with low demand charges (A-2, D), but that rate is not available with net-metering, making it very unattractive at high levels of PV penetration. As a result, that rate was not included in our analysis.

${ }^{12}$ The loss of value of PV without net metering is negative (that is, losing net metering is beneficial) in cases where the sell-back rate is greater than the value of PV with net metering. 